\title{
Regression of coronary atherosclerosis: is it possible?
}

\author{
JAMES SHEPHERD, CHRISTOPHER J PACKARD
}

\author{
From the Department of Biochemistry, Royal Infirmary, Glasgow
}

1984 was a good year. Contrary to orwellian predictions of doom it heralded a new era of confidence in the possibility of reducing the impact of coronary heart disease in the community. At a cost of $\$ 150$ million, and with a one tailed $t$ test significance of p $<0.05$, the Lipid Research Clinics Coronary Primary Prevention Trial (sponsored by the National Institutes of Health) produced convincing evidence that lowering plasma concentrations of cholesterol in symptom free hypercholesterolaemic men reduces the likelihood of their having a myocardial infarction. ${ }^{1}$ This study highlighted the graded benefit to be gained from increasing the vigour of treatment to lower blood lipids and popularised the concept that a $1 \%$ fall in total plasma cholesterol should lead to a $2 \%$ reduction in coronary heart disease risk. ${ }^{2} \mathrm{~A}$ rapid succession of additional reports ${ }^{3-5}$ culminating in the eagerly awaited Helsinki Heart Study, ${ }^{6}$ underscored the importance of cholesterol reduction in any programme designed to attack coronary disease.

The pharmaceutical industry has not been slow to appreciate the importance of these findings. New lipid lowering agents and old friends in fresh guise are being offered to the physician. This expansion widens choice, but also carries with it the need to establish the benefit/risk ratio of the regimen, which may be prescribed for the remainder of the patient's life. Ideally we would like to know whether all newly introduced lipid lowering agents are able to cut coronary morbidity and mortality, but the cost of such prospective studies is prohibitive. There is, therefore, a pressing need to identify a different, possibly softer, end point. Coronary angiography is the obvious candidate, even though it tests only one part of the overall pathophysiology of the disease. It allows us to assess the state of the lesion but cannot be

Requests for reprints to Professor James Shepherd, Department of Pathological Biochemistry, Royal Infirmary, Glasgow G4 0SF. used predictively to identify when or in whom we may expect to see an infarct. Nevertheless, this direct indicator of lesion progression or regression may provide a good measure of the efficacy of lipid lowering drugs.

\section{How realistic is it to expect that human atherosclerotic lesions can be made to regress?}

The pathologist, who sees these lesions every day, would probably take the view that the tissue damage and inflammatory response that characterise them are unlikely to respond to currently available regimens. In fact, the advanced atherosclerotic plaque with its fibrous cap, necrotic core, widespread calcification, and infiltrates of inflammatory cells appears to be a permanent, continuing feature of the patient's remaining years. In theory, however, all of these elements are amenable to mobilisation or even degradation.

Recent studies have shown that even the lipid core within the plaque ${ }^{7}$ is continually turning over, albeit slowly, and may therefore (under appropriate conditions) be leached from the lesion. Certainly, studies in animal models have shown that it is possible to mobilise arterial wall cholesterol and induce regression if a satisfactory reduction in plasma cholesterol can be achieved. ${ }^{8}$ Until recently most lipid lowering drugs could be expected to reduce cholesterol by no more than $25 \%$, and clinical investigators had to be satisfied with lesion stasis rather than regression ${ }^{39}$ as an acceptable end point of their arteriographically monitored intervention studies. Now, the availability of new, powerful lipid lowering agents may have made regression a more readily attainable objective. They also offer an improved prognosis for the increasing number of patients crippled by coronary artery disease for whom bypass grafting is viewed as the only alternative. 
The long term benefits of this procedure are limited because up to a third of the grafts will have become stenosed within a year of operation. ${ }^{10}$ Fresh hope for these patients comes from the recently published Cholesterol Lowering Atherosclerosis Study (CLAS) in which 162 men who had had coronary bypass surgery were treated by a combination of diet, colestipol, and nicotinic acid in the expectation that their remaining coronary atherosclerotic lesions might be induced to regress. ${ }^{5}$ This treatment lowered low density lipoprotein cholesterol by $43 \%$ (from 4.42 to $2.51 \mathrm{mmol} / \mathrm{l}$ ) and raised the high density lipoprotein concentration by $37 \%$ (from 1.15 to $1.57 \mathrm{mmol} / \mathrm{l}$ ), so that the ratio of total/ high density lipoprotein cholesterol was reduced almost to the value at which regression is the rule rather than the exception in animal studies. ${ }^{8}$

An additional feature of the CLAS study was that benefit of treatment was evident across the whole range of plasma cholesterol values found at entry. Even patients who would be considered to have "normal" plasma cholesterol concentrations (as low as $4.8-6.2 \mathrm{mmol} / \mathrm{l}$ ) benefited from cholesterol reduction. This finding accords with the results of the massive Multiple Risk Factor Intervention Trial, which showed that coronary risk was continuous across the population range for cholesterol concentration. ${ }^{11}$

\section{What are the implications of these findings?}

The arguments developed above have important implications for cardiologists and cardiac surgeons. The weight of evidence suggests that regression of coronary lesions is attainable, but only with vigorous and effective treatment to reduce blood lipids. In practice this means a reduction of at least $40 \%$ in low density lipoprotein cholesterol. At the moment this is only possible with combinations of drugs such as sequestrant resins coupled with nicotinic acid or clofibrate derivatives. The potential for the newly developed 3-hydroxy-3-methylglutaryl coenzyme A reductase inhibitors is considerable because by inhibiting synthesis of cholesterol, particularly in the liver, they make it possible to achieve cholesterol reductions of up to $68 \% .^{1213}$

The message for the cardiac surgeon is quite clear. Bypass grafting has an immediate impact on symptoms but does little for the prognosis of most patients unless the underlying causes of the disease are tackled. All patients who have had bypass grafts should share in the benefit that comes from treating the factors in their lifestyle that affect their coronary risk. Vigorous treatment to lower blood lipids is essential in these individuals.

\section{References}

1 Lipid Research Clinics Program. The Lipid Researcf Clinics Coronary Primary Prevention Trial Results $\mathbb{E}$ Reduction in incidence of coronary heart disease JAMA 1984;251:351-64.

2 Lipid Research Clinics Program. The Lipid Researc $\vec{P}$ Clinics Coronary Primary Prevention Trial Results II. The relationship of reduction in incidence of coronary heart disease to cholesterol lowering JAMA 1984;251:365-74.

3 Nikkila EA, Viikinkoski P, Valle M, Frick MH. Prevero tion of progression of coronary atherosclerosis bjo treatment of hyperlipidaemia: a seven year prospec tive angiographic study. $\mathrm{Br} M e d J$ 1984;289:220-3. 6

4 Arntzenius AC, Kromhout D, Barter JD, et al. DieS lipoproteins and the progression of coronary atherosclerosis. The Leiden Intervention Trial. $N$ Engl நl Med 1985;312:805-11.

5 Blankenhorn DH, Nessini SA, Johnson RL, Sanmarco ME, Azen SP, Caskin-Hemphill L. Beneficial effects of combined colestipol-niacin therapy on coronary atherosclerosis and coronary venous bypass grafte JAMA 1987;257:3233-40.

6 Frick MH, Elo O, Haapa K, et al. Helsinki heart stud叉 Primary prevention trial with gemfibrozil in middle aged men with dyslipidemia. $N$ Engl $J$ Met 1987;317:1237-45.

7 Katz SS, Small DM, Smith FR, Dell RB, Goodma DS. Cholesterol turnover in lipid phases of humaA atherosclerotic plaque. $J$ Lipid Res 1982;23:733-7. $\overrightarrow{0}$

8 Clarkson TB, Bond MG, Bullock BC, McLaughlin K Sawyer JK. A study of atherosclerosis regression in Macaca mulatta. Exp Mol Pathol 1984;41:96-118. 함

9 Levy RI, Brensicke JF, Epstein SE, et al. The influence of changes in lipid values induced by cholestyramine and diet on progression of coronary artery diseasê. Circulation 1984;69:325-37.

10 Campeau L, Enjalbert M, Lesperance J, et al. The relationship of risk factors to the development of atherosclerosis in saphenous-vein bypass grafts and progression of disease in the native circulation. $\bar{d}$ Engl J Med 1984;311:1329-32.

11 Martin MJ, Hulley SB, Browner WS, Keller LE Wentworth $D$. Serum cholesterol, blood pressure anA. mortality: implications from a cohort of 361662 medo Lancet 1986;ii:933-6.

12 Alberts AW, Chen J, Kuron G. Mevinolin: a high potent competitive inhibitor of 3-hydroxy-3-methydo glutaryl Coenzyme $\mathrm{A}$ reductase and a cholestero lowering agent. Proc Natl Acad Sci USA 1980;77:3957-61.

13 Illingworth DR. Mevinolin plus colestipol in therap for severe heterozygous familial hypercholes terolemia. Ann Intern Med 1984;101:598-604. 